\title{
Pengaruh dekadensi moral terhadap pendidikan karakter dan bimbingan konseling pada siswa Kristen
}

\author{
Stimson Hutagalung ${ }^{1}$, Rolyana Ferinia ${ }^{2}$ \\ 1,2Universitas Advent Indonesia, Bandung \\ 1stimson.hutagalung@unai.edu, 2rolyana.pintauli@unai.edu
}

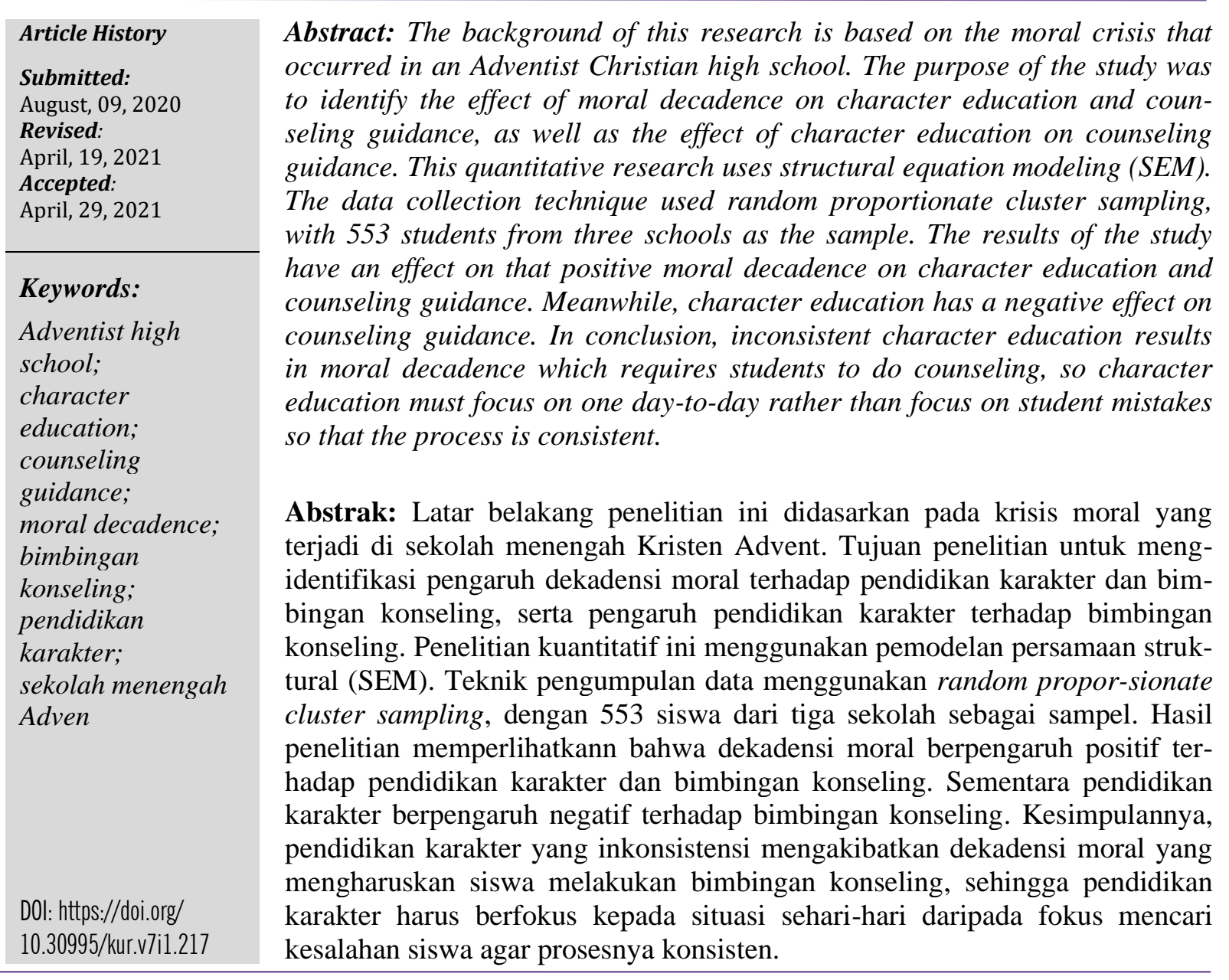

\section{Pendahuluan}

Di saat sekolah Kristen sedang mempersiapkan anak-anaknya menuju era digital, saat yang sama telah terjadi penurunan moral di berbagai tempat. Dekadensi moral di kalangan remaja semakin terlihat jelas. Itu telah menjadi salah satu masalah terbesar khususnya pada remaja saat ini. Penurunan kualitas moral terjadi dalam banyak aspek mulai dari ucapan, cara berpakaian dan perilaku. Perkelahian siswa, pemerasan, kekerasan, penindasan, dominasi senior kepada juniornya, kenakalan remaja, penyalahgunaan narkoba terjadi di mana-mana. 
Di Amerika Serikat ada 1,4 juta anggota geng terlibat dalam 33.000 kejahatan kegiatan, ${ }^{1} 11 \%$ remaja yang berusia di atas 12 tahun telah meminum alkohol dan mengalami kehamilan di luar pernikahan. ${ }^{2}$ Menurut penelitian yang dilakukan oleh Kiriakidis melaporkan tingkat ratarata pelaku dekadensi moral lebih tinggi dalam sampel pelanggar laki-laki muda (usia 16-21) ${ }^{3}$ dan komunitas siswa yang melakukannya adalah siswa sekolah menengah. ${ }^{4}$ Di beberapa negara, masalah dekadensi moral juga telah terjadi. Dekadensi moral adalah fenomena lunturnya akhlak masyarakat dengan menunjukkan perilaku moral yang negatif. ${ }^{5}$ Indonesia sebagai salah satu negara yang padat penduduknya pun mengalami hal yang sama. Hanya pada bulan Januari sampai dengan Pebruari 2019 saja telah terjadi tiga kasus kekerasan fisik, delapan kekerasan psikis, tiga kekerasan seksual, satu kali tawuran pelajar, lima korban kebijakan, dan satu korban eksploitasi. ${ }^{6}$

Fungsi pendidikan adalah untuk mengembangkan kapabilitas dan membentuk karakter. ${ }^{7}$ Pendidikan karakter dan pendidikan moral adalah benteng diri untuk melawan kemerosotan moral karena kemerosotan moral akan mengakibatkan kehancuran suatu bangsa. Dunia sedang mengalami kemunduran dan menghadapi krisis moral yang serius yang berasal dari kegagalan banyak orang terutama kaum muda karena ditinggalkannya nilai-nilai tradisional. Kemiskinan nilai mengakibatkan penyakit moral terjadi. Nilai-nilai tradisional digulingkan demi kepentingan pribadi, kebebasan yang tidak terkendali, seks bebas, penggunaan narkoba, penghindaran tanggung jawab, tidak menghormati otoritas, penolakan moralitas. ${ }^{8}$

Membentuk karakter melalui pengendalian emosi, peningkatan kerohanian, dan pengelolaan kepribadian merupakan tindakan yang perlu dilakukan saat ini, karena pembentukan karakter itu tidak terbentuk secara otomatis dan perlu dikembangkan dari waktu ke waktu melalui banyak proses. Proses pengajaran, teladan, pembelajaran, dan praktek berkelanjutannya. ${ }^{9}$ Upaya proaktif membangun kejujuran, keadilan, dan rasa hormat sudah semestinya diterapkan oleh pemerintahan tertinggi hingga terendah dan dijalankan oleh sekolahsekolah. ${ }^{10}$

${ }^{1}$ Mitchael Snyder, “There Are 1.4 Million Gang Members In The United States And More Pour Into The Country Every Single Day, Mould," Mould (2020), www.mouood.com/articles/occidentology/448-there-are-1-4million-gang-members-in-the-united-states-and-more-pour-into-the-country-every-single-day.html. .

2 Tokunbo A. Adaja and Felix A. Ayodele, "Nigerian Youths and Social Media : Harnessing the Potentials for Academic Excellence," Singaporean Journal of Business , Economics and Management Studies 1, no. 6 (2013): 56-66.

${ }^{3}$ S. P. Kiriakidis, "Moral Disengagement: Relation to Delinquency and Independence From Indices of Social Dysfunction.," International Journal of Offender Therapy and Comparative Criminology 52 (2008): 583.

4 A Bandura et al., "Mechanisms of Moral Disengagement in the Exercise of Moral Agency.," Journal of Personality and Social Psychology 71, no. 364-374 (1996).

${ }^{5}$ David R Morrow, Moral Reasoning (USA:Oxford University Press, n.d.).

${ }^{6}$ A.P. Abdi, "KPAI: 24 Kasus Anak Di Sekolah Pada Awal 2019 Didominasi Kekerasan,” Tirto.ID, last modified 2019, accessed March 25, 2020, https://tirto.id/kpai-24-kasus-anak-di-sekolah-pada-awal-2019didominasi-kekerasan-dg8o.

${ }^{7}$ Hisarma Saragih et al., Filsafat Pendidikan (Medan:Yayasan Kita Menulis, 2021).

${ }^{8}$ Elliot Turiel, The Culture of Morality:Social Development, Context, and Conflict (UK:Cambridge University Press, 2004).

${ }^{9}$ Abigail Adams, "The Need for Character Education," International Journal of Social Sciences and Humanity Studies 3, no. 2 (2011): 23-32.

${ }^{10}$ Harold S. Tuttle, “Character Education,” Religious Education 26, no. 8 (1931): 631-636. 
Melihat betapa pentingnya mencegah terjadinya kemerosotan moral bangsa khususnya kalangan anak muda, maka ada beberapa hal yang perlu diungkapkan dalam penelitian yang dilakukan di SMA Advent Jakarta ini, yaitu: bagaimana mencegah dekadensi moral yang telah terjadi, sejauh mana implementasi pendidikan karakter diperlukan, sejauh mana penerapan bimbingan dan konseling, apakah ada pengaruh dekadensi moral terhadap pendidikan karakter, apakah ada pengaruh pendidikan karakter terhadap bimbingan konseling, apakah ada pengaruh dekadensi moral terhadap pendidikan karakter.

Dekadensi moral adalah sebuah fenomena yang sering kita saksikan melalui berita di televisi, koran elektronik, dan media sosial lain. Norma yang tidak dapat diterima oleh setiap orang tetapi banyak terjadi secara praktik. Berikut ini adalah beberapa definisi dari dekadensi moral. Menurut Muraiwo dan Ugwumba, dekadensi moral adalah proses berperilaku yang menunjukkan standar moral yang rendah. ${ }^{11}$ Definisi ini dipertegas oleh Chilima yang mengatakan bahwa dekadensi moral adalah sebuah perilaku yang menunjukkan kecintaan pada kesenangan diri sendiri dengan mengikuti proses penurunan dalam etika dan moral yang berlaku di masyarakat ${ }^{12}$ Dari dua definisi di atas dapat diambil kesimpulan bahwa dekadensi moral adalah perilaku yang melanggar etika dan standar moral.

Penting untuk mengetahui karakteristik dekadensi moral. Menurut Lickona, telah terjadi penurunan moral yang awalnya dilakukan oleh masyarakat luas dan selanjutnya di kalangan remaja dengan karakteristik bahwa semakin banyak orang yang melanggar aturan, tamak, menipu, mementingkan diri, mencurangi sistem, dan mencuri. Tren dekadensi moral juga meningkat di kalangan remaja seperti terjadinya kekerasan dan vandalisme, tidak menghormati figur otoritas, pelecehan seksual, perilaku merusak diri sendiri, dan berbuat curang/tidak jujur. ${ }^{13}$ Tampaknya dekadensi moral harus segera diantisipasi oleh pihak sekolah, gereja, dan orang tua. Tanpa campur tangan pendidik dan pemangku kepentingan, kondisi tersebut kemungkinan akan terus berlanjut dan akan berakhir. Tanpa campur tangan pendidik melalui pendidikan karakter dan pemangku kepentingan, kemerosotan moral tersebut akan terus berlanjut dan berakhir dengan hilangnya banyak pemimpin gereja yang memiliki integritas.

Di zaman sekarang, manusia menghadapi krisis akut kehilangan karakter, semacam entropi nilai dan negativisme. Perkembangan karakter adalah pengembangan kualitas tertentu yang diperlukan untuk membuat hidup manusia layak untuk dijalani. Kualitas ini mungkin dalam hubungannya dengan diri sendiri dan dalam hubungannya dengan orang lain. Itu sebabnya, pendidikan memainkan peran yang sangat mendasar dalam skema pembentukan karakter. Salah satu tujuan dari pendidikan adalah untuk menghasilkan kecakapan karakter.

Pendidikan karakter adalah upaya yang disengaja untuk membantu orang memahami, peduli, dan bertindak berdasarkan nilai-nilai etika inti yang mencakup tiga komponen yaitu pikiran, perhatian, dan etika. ${ }^{14}$ Peterson menegaskan dalam Hum bahwa pendidikan karakter

\footnotetext{
${ }^{11}$ Harold S. Tuttle, Character Education: A Literature Review (Temescal Association:2015, 2015).

${ }^{12}$ Saulos Klaus Chilima, "Addressing Moral Decadence: Towards an Effective Compliance and Ethics Program †," Africa Journal of Management 5, no. 1 (2019): 98-111.

13 Thomas Lickona, Pendidikan Karakter (BandungL Nusa Media, 2008).

${ }^{14}$ Mike Frye, Character Education: Informational Handbook and Guide for Support and Implementation of the Sutdent Citizen Act. 2001. (orth Carolina: Department of Public Institution Division of Instructional Services, 2001).
} 
adalah istilah luas yang digunakan untuk menggambarkan kurikulum umum dan ciri-ciri organisasi sekolah yang mempromosikan pengembangan nilai-nilai dasar pada anak-anak di sekolah. ${ }^{15}$ Dari definisi tersebut dapat dimengerti bahwa penyelenggara pendidikan karakter adalah membantu orang untuk memahami etika di mana penyelenggaranya adalah sekolah melalui pengembangan kurikulum untuk diintegrasikan dalam pembelajaran pada setiap mata pelajaran yang diajarkan kepada siswa. Itu sebabnya penyelenggaraan pendidikan karakter di sekolah membutuhkan dukungan dari berbagai pihak terkait karena merekalah yang mengajarkan nilai etika yang paling penting untuk membentuk perilaku siswa yang baik. Pendidikan karakter juga menjadi penting ketika lemahnya peran orang tua dalam mendidik anak-anak mereka yang di saat bersama ada pengaruh negatif dari teman sebayanya. Pengaruh negatif yang dilakukan adalah pengaruh penyalahgunaan narkoba, melakukan seks bebas, menjauhi bahkan meninggalkan agama, dan melakukan kejahatan. ${ }^{16}$

Pada saat anak memasuki sekolah, peran akademik karakter dilengkapi oleh guru sekolah. Winton menjelaskan bahwa pendidikan karakter adalah merupakan upaya sungguhsungguh guru untuk mengajarkan pendidikan karakter serta mengembangkan perilaku siswa. ${ }^{17}$ Karakter yang baik meliputi pemahaman, kesadaran, dan tindakan yang didasarkan pada nilai-nilai etika inti. Oleh karena itu, pendekatan holistik diperlukan dalam pendidikan karakter untuk mengembangkan aspek kognitif dari perilaku emosional dan moral. Josephson Institute menyebutkan ada enam pilar pendidikan karakter yaitu dapat dipercaya, sikap hormat, memiliki rasa tanggung jawab, memiliki jiwa kebangsaan, peduli sesama, dan mampu bersikap adil. Dapat dipercaya adalah menyatakan dan melakukan yang benar, memiliki reputasi yang baik bersikap jujur dan dapat diandalkan dalam melaksanakan tugas dan kewajiban yang diembankan kepadanya. Rasa hormat adalah berbicara tentang tindak tanduk seseorang karena dia kagum, menghargai, dan mempercayai orang lain. Memiliki rasa tanggung jawab adalah bekerja dengan sungguh-sungguh dengan hasil yang memuaskan, memenuhi janji yang diberikan, dan bertanggung jawab atas kegagalan yang dilakukan. Memiliki jiwa kebangsaan adalah memiliki hubungan yang erat dengan negara dan menaati hukum yang berlaku. Peduli sesama adalah memikirkan kepentingan orang lain dan membantunya. Mampu bersikap adil adalah ketika seseorang dapat menempatkan sesuatu pada porsinya. ${ }^{18}$

Penelitian yang dilakukan oleh Nurhasanah and Qathrin Nida menjelaskan bahwa karakter siswa dibentuk melalui proses konseling yang dilakukan oleh guru bimbingan dalam bentuk nasihat. ${ }^{19}$ Nurul Atieka juga melakukan penelitian yang berhubungan dengan pembentukan karakter terhadap pendekatan bimbingan konseling, hasilnya adalah pembentukan karakter secara umum yang bukan holistik telah dijalankan melalui guru bimbingan dan konseling melalui layanan informasi dan bimbingan kelompok. ${ }^{20}$ Dari dua penelitian ini

\footnotetext{
${ }^{15}$ Muhammad Yaumi Hum, Pendidikan Karakater (Jakarta: Prenadamedia Group, 2014).

${ }^{16}$ Samani and Hariyanto, Pendidikan Karakter (Bandung: Remaja Rosdakarya Offset, 2016).

${ }^{17}$ Sue Winton, "Character Education: Implications for Critical Democracy" 1, no. 1 (2012).

${ }^{18}$ Samani and Hariyanto, Pendidikan Karakter.

${ }^{19}$ Nurhasanah Nurhasanah and Qathrin Nida, "Character Building of Students By Guidance and Counseling Teachers Through Guidance and Counseling Services,” Jurnal Ilmiah Peuradeun 4, no. 1 (2016): 65 .

${ }^{20}$ Nurul Atieka, "Character Building of Students With Counseling Services Approach," GUIDENA: Jurnal Ilmu Pendidikan, Psikologi, Bimbingan dan Konseling 4, no. 1 (2014): 12.
} 
pendidikan karakter dilakukan oleh guru bimbingan konseling bukan melalui pendekatan intensif tetapi hanya melalui layanan informasi yang informasi yang sifatnya pasif, dan melalui nasihat dan melakukan bimbingan kelompok.

Layanan bimbingan konseling di sekolah memiliki peran yang penting untuk mengarahkan siswa selama proses pendidikan. Layanan ini perlu menggabungkan kegiatan akademik dan pembentukan karakter dengan pendekatan budaya dan spiritual yang baik. Penggabungan kegiatan yang bersifat akademik adalah segala kegiatan yang berhubungan dengan pendidikan. Layanan bimbingan dan koseling harus ada di setiap sekolah dan berintegrasi dengan kurikulum dan proses belajar-mengajar secara akademik disaat yang sama layanan ini harus mengkorelasikannya dengan agama yang dianut dan budaya yang dimiliki setiap siswa. ${ }^{21}$

Tujuan penelitian ini adalah untuk mengidentifikasi pengaruh dekadensi moral terhadap pendidikan karakter dan bimbingan konseling, serta pengaruh pendidikan karakter terhadap bimbingan konseling. Penelitian ini menggunakan teori dasar pendidikan karakter dan degenerasi moral dari Lickona ${ }^{22}$ dan teori bimbingan dan konseling dari Giyono. ${ }^{23}$ Hubungan antara dekadensi moral dan dengan layanan bimbingan dinyatakan oleh Lickona, yang menyebutkan bahwa kemerosotan moral telah menjadi masalah dunia dan untuk mengatasinya perlu keterlibatan pimpinan, guru agama, guru pengajar dan guru bimbingan dan konseling. Guru agama dan guru bimbingan konseling dapat menjadi penghubung yang baik karena peran Guru Pendidikan Agama Kristen sebagai komunikator merupakan cara yang efektif untuk menyelesaikan konflik siswa.

Hal tersebut dikuatkan oleh penelitian yang dilakukan oleh Mallinckrodt dengan hasil bahwa studi tentang perilaku moral, masalah multikultural, minoritas seksual, koping, kesejahteraan, dukungan sosial, dan psikoterapi berhubungan dengan konseling. ${ }^{24}$ Britwum menjelaskan bahwa salah satu langkah yang harus digunakan untuk memerangi dekadensi moral adalah pembentukan aturan, pengawasan orang tua dan konseling sekolah agar tercipta moral yang baik. Sehingga sekolah perlu mengadakan lokakarya kepada guru, siswa untuk mendapatkan kesadaran dan tanggung jawab optimal. ${ }^{25}$ Secara teori memang ada hubungan antara dekadensi moral dengan layanan bimbingan dan konseling, tetapi secara praktik, masih ada cela masalah yang terjadi yaitu tentang kualifikasi seorang pembimbingan konseling di sekolah. Mengingat banyak tugas dan tanggung jawab seorang pembimbing konseling, seperti orientasi, layanan pengenalan siswa, konseling, konseling kelompok, konsultasi dan sebagainya, maka perlu beberapa orang khusus yang bekerja di posisi tersebut dengan kualifikasi yang sesuai dan yang digaji hanya untuk mengerjakan tugasnya tanpa tugas rangkap. ${ }^{26}$ Pendanaan, tidak konsisten menyelenggarakan bimbingan dan fasilitas yang memadai juga

${ }^{21}$ Giyono, Bimbingan Konseling (Yogyakarta: Media Akademi, 2015).

${ }^{22}$ Lickona, Pendidikan Karakter.

${ }^{23}$ Giyono, Bimbingan Konseling.

${ }^{24}$ Brent Mallinckrodt, "Addressing the Decline in Counseling and Supervision Process and Outcome Research in the Journal of Counseling Psychology," The Counseling Psychologist 39, no. 5 (2011): 701-714.

${ }^{25}$ Francis Britwum et al., "Perceived Causes and Effects of Moral Decadence among Some Selected Senior High Schools in the Kumasi Metropolis, Ghana," The International Journal of Humanities \& Social Studies 8, no. 5 (2020).

${ }^{26}$ Kenan Sevinc, Sibel Tasci, and Elif Demir, "Some Problems of Psychological Counseling and Guidance System in Turkey," Procedia - Social and Behavioral Sciences 46 (2012): 1056-1063, http://dx.doi.org/10.1016/j.sbspro.2012.05.248. 
menjadi masalah. ${ }^{27}$ Inilah yang menjadi celah (gap) antara pentingnya dekadensi moral ditangani dengan teratur dan profesional, tetapi tidak didukung dengan penyiapan tenaga yang kompeten agar dia dapat konsisten menyelenggarakan bimbingan, dan dana dan fasilitas yang memadai.

Pengaruh dekadensi moral terhadap pendidikan karakter dijelaskan oleh Nucci \& Narvaez. Mereka menjelaskan bahwa pendidikan karakter adalah kegiatan berbasis sekolah yang dirancang oleh sekolah untuk mempersiapkan perilaku siswa. ${ }^{28}$ Sedangkan Hartono juga menjelaskan bahwa pendidikan karakter merupakan alat penting untuk membentuk karakter siswa yang pengelolaannya dilaksanakan oleh layanan bimbingan dan konseling. ${ }^{29}$ Guru dan pembmbing konseling memiliki peran aktif untuk menanamkan kebiasaan yang baik yang pada akhirnya akan membentuk karakternya. Terjadi perbedaan yang signifikan secara statistik antara siswa yang menerima layanan bimbingan dan konseling dan mereka yang tidak. Siswa yang menerima layanan bimbingan dan konseling lebih berkembang dalam keterampilan interpersonal, belajar, kejuruan dan pemecahan masalah daripada teman-temannya yang tidak menerima bimbingan. ${ }^{30}$. Dari beberapa hasil penelitian, mereka menyatakan bahwa pendidikan karakter sangat diperlukan, tetapi masih saja ada kesenjangan yang terjadi sehingga penerapan pendidikan karakter tidak berjalan sesuai dengan harapan. Gao dan Wang menguraikan bahwa sesungguhnya ada masalah dasar dari pendidikan moral yaitu pertama, masih ada kurang pemahaman yang objektif tentang bagaimana menerapkan pendidikan karakter yang efektif untuk meningkatkan kesadaran dan memengaruhi pengendalian diri. Kedua, kurangnya pemahaman mendalam tentang kompleksitas kehidupan di sekolah (kurang berbaurnya penyelenggara pendidikan dengan kehidupan anak-anak di sekolah di luar proses belajar dan mengajar) sehingga penerapan yang tepat proses pendidikan karakter tidak berjalan dengan baik. Kesenjangan ini yang membuat dekadensi moral masih saja menjadi momok yang menakutkan, dan pendidikan karakter berjalan di tempat. ${ }^{31}$

Pengaruh antara pendidikan karakter dengan layanan bimbingan dan konseling dijelaskan oleh Njoku yang menunjukkan bahwa moral siswa dapat dibangun melalui kurikulum pendidikan Kristen secara kreatif untuk menolong siswa memahami konsep diri, peran, dan tanggung jawabnya. ${ }^{32}$ Pendidikan karakter ini juga didukung melalui layanan bimbingan dan konseling. Itu sebabnya, seorang pembimbing konseling perlu mempersiapkan semua praktik

${ }^{27}$ Monicah Lydia. J Boitt, "Evaluation of the Challenges in the Implementation of the Guidance and Counselling Programme in Baringo County Secondary Schools, Kenya," Journal of Education and Practice 7 , no. 30 (2016): 27-34, http://search.ebscohost.com/login.aspx?direct=true\&db=eric\&AN=EJ1118929\&site=ehost-live.

${ }^{28}$ T Nucci, L., Narvaes., Krettenauer, Handbook of Moral and Character Education (New York: Routledge, 2014). 2011

${ }^{29}$ Hartono, "Implementasi Pendidikan Karakter Pada Layanan Bimbingan Dan Konseling," Wahana,

${ }^{30}$ Abigail Mukuwa Tuchili, "Effects of Guidance and Counselling Services on Students' Interpersonal, Study, Vocational and Problem-Solving Skills in Selected Public Universities in Zambia," International Journal of Humanities, Social Sciences and Education 3, no. 12 (2016).

${ }^{31}$ Desheng Gao and Di Wang, "Rethinking 'Basic Issues' in Moral Education," ECNU Review of Education (2020): 209653112095032.

32 Johanes Waldes Hasugian, "Kurikulum Dan Pembelajaran Warga Jemaat Dewasa Di Gereja," KURIOS (Jurnal Teologi dan Pendidikan Agama Kristen) 5, no. 1 (2019): 36-53. 
dan prinsip untuk pembentukan karakter, kepribadian, dan perilaku siswa. ${ }^{33}$ Sebuah penelitian yang menggunakan pendekatan terapi yang disebut dengan Rational Emotive Therapy (RET) sebagai pendekatan konseling terhadap kecerdasan moral dibandingkan dengan terapi yang menggunakan pendekatan Client-Centered Therapy (CCT) terhadap siswa disebuah sekolah temuannya adalah bahwa pendekatan kecerdasan siswa dengan prestasi belajar lambat yang di konseling dengan pendekatan konseling RET lebih tinggi dibandingkan dengan pendekatan CCT, dan sebaliknya pendekatan siswa yang prestasi belajarnya tinggi, maka pendekatan yang lebih efektif adalah dengan menggunakan pendekatan CCT. Dari hasil penelitian ini maka adanya perbedaan memberikan pendidikan karakter terhadap siswa dengan prestasi lambat dan tinggi ${ }^{34}$. Ini yang tidak diperhatikan oleh pihak sekolah saat memberikan proses pendidikan karakter. Mereka menyamaratakan pendidikan karakter.

Dari penjelasan tentang masing-masing variabel maka kebaruan (state of art) dari penelitian ini adalah dekadensi moral harus diperangi dengan seperangkat peraturan sekaligus dengan proses bimbingan konseling yang tepat dari pihak-pihak terkait (pihak sekolah, orang tua siswa, dan siswa itu sendiri) dan diperkuat dengan pemilihan tenaga pembimbing yang memiliki kompotensi dibidangnya tanpa diberikan tugas tambahan selain yang tidak berhubungan dengan proses bimbingan dan konseling agar dia dapat melakukan proses konseling dengan teratur, konsisten dan optimal. Pendidikan moral juga harus "membumi" artinya tenaga pendidik perlu untuk melihat tingkah laku siswa diluar jam kelas untuk mengamati masalah moral apa yang sesungguhnya terjadi. Pendidikan moral juga harus memerhatikan kecerdasan intelektual siswa agar dapat menentukan pendekatan konseling yang terbaik.

\section{Metode}

Penelitian ini dilakukan di Sekolah Advent yang didirikan oleh Yayasan Gereja Masehi Advent Hari Ketujuh. Agama mayoritas siswa yang bersekolah di semua sekolah Advent adalah Advent Hari Ketujuh, walaupun ada juga siswa yang beragama non-Advent. Penelitian ini menggunakan desain deskriptif ${ }^{35}$ untuk menggambarkan masing-masing variabel dan desain sebab akibat (explanatory causal). SPSS dan Structural Equation Modeling Amos digunakan sebagai alat untuk menganalisis data. Populasi dalam penelitian ini adalah semua siswa yang terdaftar ditiga Sekolah SMU Advent di Jakarta. Pengolahan data menggunakan random proporsionate cluster sampling. Sampel sebanyak 553 siswa dengan menggunakan Slovin sebagai teknik pengambilan sampel dengan presisi 5\%. 553 sampel diperoleh dari perhitungan proporsional random sampling dari tiga sekolah; Perguruan Advent Jakarta, Perguruan Advent Dharma Putra, Perguruan Advent Ciracas. Subjek penelitiannya adalah sekolah-sekolah SMU Advent di Jakarta. Penelitian ini menggunakan wawancara kepada pejabat struktural, guru-guru dan siswa dan kuesioner yang dibagikan kepada siswa di masing-masing sekolah dengan Skala Likert. Untuk mengukur dekadensi moral, penelitian ini mengadopsi dari Lickona berdasarkan lima dimensi dan 14 item. Contoh item adalah

\footnotetext{
${ }^{33}$ P.U. Ekpang, "Counselling Practices As a Bench-Mark for Behaviour Modification-Implication for Youth Development," International Journal of Education and Researce 4, no. 5 (2016): 25-36.

${ }^{34}$ Aisyah Aisyah, "Effect of Counseling Approach and Learning Achievement to Moral Intelligence," JETL (Journal Of Education, Teaching and Learning) 3, no. 1 (2018): 87.

${ }^{35}$ Eko Sudarmanto et al., Desain Penelitian Bisnis: Pendekatan Kuantitatif (Medan:Yayasan Kita Menulis, 2021).
} 
"pengalaman bullying di sekolah" Untuk mengukur pendidikan karakter, diadopsi dari Lickona (berdasarkan enam dimensi dan 12 item. Contoh item adalah "Saya setia pada agama saya". Untuk mengukur bimbingan dan konseling, diadopsi dari Schmidt berdasarkan enam dimensi dan 11 item. Contoh item adalah "konselor senang mendengarkan masalah siswa"

Penelitian ini menggunakan teori dasar pendidikan karakter dan degenerasi moral dari Lickona ${ }^{36}$ dan teori bimbingan dan konseling dari Giyono. ${ }^{37}$ Hubungan antara layanan bimbingan dan konseling dan dekadensi moral dinyatakan oleh Lickona. Dia menyebutkan bahwa kemerosotan moral telah menjadi masalah dunia dan untuk mengatasinya perlu keterlibatan pimpinan, guru agama, guru pengajar dan guru bimbingan dan konseling. Guru agama dan guru bimbingan konseling dapat menjadi penghubung yang baik karena peran Guru Pendidikan Agama Kristen sebagai komunikator merupakan cara yang efektif untuk menyelesaikan konflik siswa ${ }^{38}$

\section{Hasil dan Pembahasan}

\section{Mencegah Terjadinya Dekadensi Moral}

Hasil deskriptif degenerasi moral siswa tiga tertinggi adalah sebagai berikut: $60,6 \%$ siswa menyaksikan temannya meminum minuman beralkohol, $66.5 \%$ siswa melihat temannya menggunakan narkoba, $46.8 \%$ siswi melihat teman wanitanya mengalami pelecehan seksual. Hasil data kemudian ditegaskan dengan wawancara yang dilakukan kepada kepala sekolah, guru, dosen bimbingan dan konseling dan beberapa siswa yang diambil secara random. Wawancara mengenai "teman yang meminum alkohol" telah dilakukan kepada beberapa siswa lelaki yang diambil random dari setiap kelas menjelaskan bahwa memang mereka menyaksikan temannya minum minuman beralkohol karena diajak disalah satu rumah teman (biasanya malam minggu dan hari libur), di acara pesta ulang tahun, atau di acara khusus lainnya. Tidak benar-benar mabuk dan mereka tidak pernah meminum alkohol di sekolah.

Wawancara mengenai menyaksikan "teman mengonsumsi narkoba" menyebutkan bahwa jenis narkoba yang mungkin mereka gunakan adalah jenis pil. Mereka mengetahui bahwa kemungkinannya adalah jenis pil dari cerita-certa yang disampaikan oleh temantemannya. Mereka juga tidak melihat temannya memasukkan pil tersebut ke mulut, tetapi mereka hanya menduga-duga dari tingkah lakunya. Sehingga hasil yang menyatakan $66.5 \%$ menyaksikan temannya mengonsumsi narkoba masih berdasarkan asumsi perilaku "orangnya bingung-bingung", "nggak nyambung waktu diajak bicara", "gelisah", "berani melawan". Wawancara berikutnya adalah dengan memanggil beberapa siswi perwakilan dari setiap kelas yang diambil secara random untuk memperjelas hasil kuesioner mengenai menyaksikan "siswi melihat temannya dilecehkan." Mereka bercerita bahwa pelecehan yang dilakukan dengan menggoda, mencolek bagian-bagian tertentu seperti bagian dada, memegang tangan, dan menceritakan humor yang menjurus ke seks. Mereka melakukannya hanya untuk becanda, tetapi para wanita tidak sedang diperlakukan seperti itu.

\footnotetext{
${ }^{36}$ Lickona, Pendidikan Karakter.

${ }^{37}$ Giyono, Op. Cit.

${ }^{38}$ Pitersina Christina Lumamuly, "The Role of Christian Religious Education Teacher in Preventing and Resolving Student Conflicts," KURIOS (Jurnal Teologi dan Pendidikan Agama Kristen) 7, no. 1 (2021): 53-60.
} 
Tiga orang guru bimbingan konseling ditanya sehubungan dengan hasil kuesioner dan hasil wawancara terhadap siswa, kemudian mereka memberikan keterangan sebagai berikut, "banyak dari siswa mereka berasal dari keluarga yang tidak utuh, orang tuanya bercerai atau orang tuanya sibuk dengan urusannya masing-masing sehingga terjadi inkonsisten dalam mendidik anak. Setiap hari anak berjuang untuk menentukan tindakan yang benar dan salah, dan karena bingung, mereka akan memilih tindakan yang menguntungkan dirinya daripada melakukan yang benar. Pelarian mereka adalah kepada hal-hal negatif seperti perkelahian, minum minuman keras, bahkan mengonsumsi narkoba. Sering kali kondisi itu sudah dibawa dari rumah. Kami hanya bisa mencegah agar tidak terjadi disekolah dan disaat yang sama kami melakukan proses konseling untuk mengubah perilakukan. Diwaktu-waktu tertentu kami juga akan mengadakan inspeksi mendadak.

Beberapa guru akan masuk ke ruangan dan memeriksa isi tas, laci, tubuh siswanya untuk mencari barang yang dilarang tersebut. Mereka juga akan memeriksa telepon selular setiap siswa untuk melihat peredaran gambar/video porno melalui media sosial. Jika ada siswa yang melakukan pelanggaran, maka siswanya akan dibawa ke pembmbing konseling (bagian penyuluhan) untuk dapat diberikan arahan dan bimbingan, dan barang akan disimpan untuk menjadi barang bukti. Ketika diberitahukan tentang telah terjadi pelecehan seksual siswa terhadap siswi seperti menggoda, mencolek, memegang, dan menceritakan humor seks, mereka cukup terkejut karena diluar perhatian mereka. Dan mereka berjanji untuk mulai memerhatikan dan memberikan seminar-seminar anak muda.

Dari hasil deskriptif ini maka dapat simpulkan bahwa pertama, usia anak siswa 13-18 tahun menganggap bahwa minum minuman yang beralkohol adalah sebagian dari gaya hidup dengan tujuan untuk menjaga gengsi dengan sesama teman, agar mereka diperhitungkan di lingkungannya. Kedua, siswa yang mengonsumsi narkoba dikarenakan tidak dipenuhinya kebutuhan emosional dari orang tuanya. Mereka butuh ketenangan dan kebahagiaan semu yang dapat diperoleh dari sebutir pil atau jenis narkoba lainnya. Ketiga, pelecehan seksual terjadi karena ketidakmengertian pria yang menganggap bahwa apa yang mereka lakukan hanya sebatas candaan saja, sedangkan dari pihak wanita, mereka telah merasa dilecehkan.

Perlu ada kerjasama segitiga sama sisi antara pihak sekolah, orang tua dan anak. Segitiga sama sisi ini melambangkan bahwa sekolah, orang tua dan anak memiliki motivasi, komitmen, dan keterikatan yang sama kuat untuk mencegah kemerosotan moral siswa. Mengajak orang tua untuk terlibat bersama-sama dengan pihak sekolah adalah cara yang efektif. Caranya adalah dengan membentuk kelompok konseling dalam praktek ${ }^{39}$ dengan pembimbing rohani dari gabungan orang tua. Satu kelompok terdiri dari dua orang tua (bukan pasangan suami istri) tetapi dengan jenis kelamin yang sama (ibu dengan ibu atau bapak dengan bapak) kemudian pihak sekolah akan menyeleksi siswa siswi yang bermasalah dan membagi mereka ke dalam kelompok orang tua yang bukan orang tuanya. Proses bimbingan dapat dilakukan selama satu semester atau bahkan satu tahun. Kemudian mereka akan berinteraksi dan melakukan proses bimbingan dengan menjalin hubungan pertemanan.

\footnotetext{
${ }^{39}$ Stimson Hutagalung et al., Konseling Pastoral (Medan:Yayasan Kita Menulis, 2021).
} 
Setelah hubungan pertemanan terjalin dan kepercayaan muncul, maka perlu untuk menetapkan ekspektasi. ${ }^{40}$ Diharapkan dengan metode ini para siswa dan siswi dapat berubah.

\section{Implementasi Pendidikan Karakter di SMA Advent Jakarta}

Hasil deskriptif pada tabel 1, ditemukan bahwa $87.7 \%$ siswa tidak memperlakukan orang dengan sopan, $82.5 \%$ tidak dapat menyimpan rahasia, dan $78.6 \%$ tidak memiliki agama. g berada dan mengunggahnya di Facebook, Instagram, Line, WhatsApp. Sambil menunggu jumlah "like" mengakibatkan mereka tidak pandai berkomunikasi secara nyata. Setiap hari mereka akan memegang dawainya, membuka aplikasi, menutup aplikasi, membuka lagi dan menutup lagi, begitulah yang terjadi setiap menit. Ada beberapa cara yang telah dilakukan oleh pihak sekolah yaitu pertama, setiap guru diharuskan untuk mengajarkan pendidikan karakter dalam setiap mata pelajaran yang diajarkan dengan cara mengintegrasikan setiap mata pelajaran kepada iman dan kerohanian. Kedua, setiap guru harus mengembangkan nilainilai agama dalam setiap mata pelajaran yang diajarkan. Ketiga, mengembangkan kurikulum nasional berbasis kompetensi yang mencakup dasar-dasar kepribadian, sikap, dan perilaku. Keempat, guru bimbingan dan konseling memberikan pendidikan karakter selama satu jam setiap minggu di setiap kelas.

\section{Penerapan Layanan Bimbingan dan Konseling di Sekolah Advent Jakarta}

Hasil kuesioner tentang peran pembmbing konseling di sekolah adalah sebagai berikut: pembimbing konseling tidak kompeten $79.5 \%$, pembmbing konseling tidak dapat menyimpan rahasia, 75.7\% dan pembmbing konseling tidak dapat menjalin hubungan baik dengan siswa, 76.3\%. (Tabel. 2). Dari tiga sekolah Advent, hanya ada satu sekolah yang memiliki layanan bimbingan penyuluhan dengan seorang psikolog. Ia adalah seorang wanita, dan telah bekerja selama satu tahun di sekolah tersebut. Selain sebagai seorang pembmbing konseling, dia juga merangkap sebagai guru musik dan memberikan les musik kepada siswanya. Waktunya lebih banyak digunakan untuk pelayanan musiknya daripada melakukan bimbingan dan konseling. Di dua sekolah lainnya, peran pembmbing konseling di rangkap oleh salah satu guru wali kelas yang tidak mempunyai kompetensi di bidang bimbingan siswa. Mereka lebih sering mencari siswa yang melakukan kesalahan seperti terlambat datang ke sekolah atau kabur dari kelas daripada membentuk karakter siswa. Temuan di atas telah menguatkan jawaban responden pada indikator "konselor di sekolah tidak kompeten". Bukti lain yang menguatkan dari hasil deskriptif, pertama, sebagian besar siswa tidak menyadari bahwa di sekolahnya ada layanan bimbingan dan konseling, Kedua, beberapa siswa tidak menyadari kehadiran seorang penasihat di sekolah, ketiga, beberapa dari mereka menganggap guru wali adalah seorang penasihat.

\footnotetext{
${ }^{40}$ Stimson Hutagalung, Pendampingan Pastoral (Medan:Yayasan Kita Menulis, 2021).
} 
Tabel 1: Hasil Deskriptif setiap Variabel

\begin{tabular}{|c|c|c|c|c|}
\hline No & Dimensi dan Indikator & Ya & $\begin{array}{c}\text { Kadang- } \\
\text { kadang }\end{array}$ & Tidak Pernah \\
\hline \multicolumn{5}{|c|}{ Dekadensi Moral } \\
\hline 1 & Mengalami intimidasi & $43.8 \%$ & $18.4 \%$ & $37.8 \%$ \\
\hline 2 & Menyaksikan teman tauran & $22.1 \%$ & $45.4 \%$ & $32.4 \%$ \\
\hline 3 & Mengalami kehilangan barang di sekolah & $23.3 \%$ & $21.5 \%$ & $55.2 \%$ \\
\hline 4 & Melihat teman menyontek saat ujian & $20.3 \%$ & $26,2 \%$ & $53.5 \%$ \\
\hline 5 & Melihat teman menyontek tugas temannya & $20.1 \%$ & $27.3 \%$ & $52.6 \%$ \\
\hline 6 & Tidak hormat kepada guru & $20.1 \%$ & $35.3 \%$ & $44.7 \%$ \\
\hline 7 & Melawan guru & $21.5 \%$ & $33.3 \%$ & $54.2 \%$ \\
\hline 8 & Melihat teman mengejek temannya & $18.6 \%$ & $31.5 \%$ & $59.9 \%$ \\
\hline 9 & Ada komplotan & $37.1 \%$ & $23 \%$ & $40.8 \%$ \\
\hline 10 & Mengucapkan kata makian & $21.3 \%$ & $38.7 \%$ & $40 \%$ \\
\hline 11 & Membaca/menonton pornografi & $46.8 \%$ & $18.3 \%$ & $34.9 \%$ \\
\hline 12 & Melihat teman wanita di lecehkan secara seksual & $46.8 \%$ & $21.3 \%$ & $31.8 \%$ \\
\hline 13 & Teman menggunakan narkoba & $66.5 \%$ & $3,3 \%$ & $31.3 \%$ \\
\hline 14 & Teman meminum alkohol & $60.6 \%$ & $8.1 \%$ & $31.3 \%$ \\
\hline \multicolumn{5}{|c|}{ Pendidikan Karakter } \\
\hline 15 & Dapat menyimpan rahasia & $17.5 \%$ & $36.2 \%$ & $46.3 \%$ \\
\hline 16 & Setia pada agama & $22.2 \%$ & $11.8 \%$ & $66.8 \%$ \\
\hline 17 & Memperlakukan orang lain dengan baik & $7.4 \%$ & $73.2 \%$ & $19.2 \%$ \\
\hline 18 & Sopan & $12.3 \%$ & $51.5 \%$ & $36.2 \%$ \\
\hline 19 & Tidak sanggup menyakiti hati teman & $17.7 \%$ & $47.4 \%$ & $35.4 \%$ \\
\hline 20 & Tidak suka menyalahkan & $15.4 \%$ & $53 \%$ & $31.6 \%$ \\
\hline 21 & Jangan pernah mengambil keuntungan dari orang lain & $16.3 \%$ & $49.4 \%$ & $34.4 \%$ \\
\hline 22 & Mengkuti peraturan sekolah & $14.6 \%$ & $48.6 \%$ & $36.7 \%$ \\
\hline 23 & Tidak pernah berlaku kasar & $13 \%$ & $71.6 \%$ & $15.4 \%$ \\
\hline 24 & Cepat merespons kebutuhan orang lain & $11.9 \%$ & $60.6 \%$ & $27.5 \%$ \\
\hline 25 & Murah hati kepada yang membutuhkan & $13.6 \%$ & $59 \%$ & $27.5 \%$ \\
\hline 26 & Saya mematuhi undang-undang negara & $19.7 \%$ & $30 \%$ & $50.3 \%$ \\
\hline \multicolumn{5}{|c|}{ Layanan Bimbingan dan Konseling } \\
\hline 27 & Mahasiswa merasa aman saat menceritakan masalahnya & $24.6 \%$ & $26 \%$ & $49.7 \%$ \\
\hline 28 & Konselor merahasiakan apa yang diceritakan & $23.9 \%$ & $15.1 \%$ & $60.6 \%$ \\
\hline 29 & Konselor membina hubungan yang baik dengan setiap siswa & $23.7 \%$ & $14.1 \%$ & $62.2 \%$ \\
\hline 30 & Saya bersedia mengikuti nasihat pembmbing konseling & $16.8 \%$ & $41.8 \%$ & $41.2 \%$ \\
\hline 31 & $\begin{array}{l}\text { Perilaku buruk siswa dapat berubah setelah mendengarkan } \\
\text { saran pembmbing konseling }\end{array}$ & $12.3 \%$ & $59.5 \%$ & $28.2 \%$ \\
\hline 32 & $\begin{array}{l}\text { Konselor menggabungkan bimbingan dengan pelajaran } \\
\text { sekolah untuk mendorong pencapaian siswa }\end{array}$ & $19.6 \%$ & $26.6 \%$ & $54.6 \%$ \\
\hline 33 & Saya yakin dengan kemampuan pembmbing konseling & $13.7 \%$ & $40.9 \%$ & $45.4 \%$ \\
\hline 34 & $\begin{array}{l}\text { Konselor adalah orang yang kompeten sesuai dengan latar } \\
\text { belakang pendidikan }\end{array}$ & $22.2 \%$ & $22.9 \%$ & $56.6 \%$ \\
\hline 35 & $\begin{array}{l}\text { Seorang pembmbing konseling memperhatikan perilaku } \\
\text { siswa setiap hari }\end{array}$ & $21 \%$ & $31 \%$ & $48.1 \%$ \\
\hline 36 & Konselor adalah orang yang ramah & $20.1 \%$ & $34.4 \%$ & $45.6 \%$ \\
\hline 37 & Kepala sekolah merangkap sebagai penasihat & $26.2 \%$ & $23.3 \%$ & $50.5 \%$ \\
\hline
\end{tabular}

\section{Good-Of-Fit}

Goodness-of-Fit adalah ukuran kesesuaian input aktual atau observasi (kovarians atau matriks korelasi) dengan prediksi model yang diusulkan. Tiga pengukuran untuk mengukur Goodness-of-fit yaitu ukuran kecocokan absolut, ukuran kecocokan inkremental, dan ukuran 
kecocokan parsimoni. Ukuran kecocokan absolut: hasilnya adalah Chi-square $=346.279$, Derajat kebebasan $=109$, Tingkat probabilitas $=.000, \mathrm{CMIN} / \mathrm{DF}=3.177$. Menurut Wheaton et.al dalam nilai rasio lima atau $\leq$ lima mewakili ukuran yang masuk akal. ${ }^{41}$ RMSEA $=0,063$. Nilai RMSEA 0,05 hingga 0,08 mendapatkan ukuran yang dapat diterima. ${ }^{42}$ Ukuran kecocokan inkremental: NFI $=0,953$. Indeks Normed Fit yang direkomendasikan sama dengan atau lebih besar dari 0,90. Ukuran Fit Parsimonious: PNFI $=0,764$. Nilai parsimonious normal fit index (PNFI) yang disarankan adalah 0,60-0,90.

\section{Model Pengukuran Fit}

Pengukuran multidimensi dan keandalan konstruk masing-masing konstruk menggunakan reliabilitas komposit. Hasil reliabilitas adalah MD 0,725, CE 0,824, BC 0,830 semuanya di atas 0,70. Tingkat reliabilitas yang sesuai lebih besar dari 0,70, menggunakan Alpha Cronbach. ${ }^{43}$ Dan hasil validitas konvergen semua indikator di atas 0.70 .

\section{Hasil Uji Hipotesis}

Hasil uji hipotesis dengan menggunakan AMOS menunjukkan bahwa ketiga variabel tersebut signifikan. Hasil uji hipotesis ditunjukkan pada Tabel 4 di bawah ini.

\section{Tabel 3: Hasil Hipotesis}

\begin{tabular}{|l|l|l|l|l|l|}
\hline Variabel & R-Square & C.R. & Sig. & Keterangan & Kesimpulan \\
\hline Charactered<--- Moraldecl & 0.492 & 7.465 & $* * *$ & H01 Ditolak & Signifikan \\
\hline Guidancecounc<---- Charactered & 0.778 & -9.365 & $* * *$ & H02 Ditolak & Signifikan \\
\hline Guidancecounc <---Moraldecl & 0.074 & 3.769 & $* * *$ & H03 Ditolak & Signifikan \\
\hline
\end{tabular}

\section{Pengaruh Kemerosotan Moral terhadap Pendidikan Karakter}

Koefisien variabel laten eksogen dekadensi moral terhadap pendidikan karakter variabel laten endogen adalah 7.465; ini menunjukkan adanya hubungan positif antara dekadensi moral dan pendidikan karakter. Pencegahan dekadensi moral dapat di antisipasi dengan menerapkan pendidikan karakter yang baik. Nilai t-hitung 7,465 lebih besar dari batas kritis yang ditentukan $\pm 1,96$, sehingga $\mathrm{H} 01$ = ditolak dan $\mathrm{Ha}_{1}$ diterima yang berarti ada pengaruh dekadensi moral pada pendidikan karakter. Analisis telah dilakukan untuk menghitung koefisien determinasi dengan mengonfirmasi pengaruh dekadensi moral pada pendidikan karakter. Hasil statistik menunjukkan bahwa pengaruh dekadensi moral pada pendidikan karakter adalah 49,2\%. Artinya untuk sekolah Advent di Jakarta, pendidikan karakter dapat menekan kemerosotan moral mahasiswanya. Hal ini dikuatkan oleh penelitian yang dilakukan oleh Nucci, yaitu peran pendidikan karakter di sekolah harus berkontribusi pada pengembangan moral siswa. ${ }^{44}$ Abourjilie mengatakan bahwa pendidikan karakter dapat mengatasi masalah kritis seperti ketidakhadiran siswa, masalah disiplin, penyalahgunaan narkoba, kekerasan

${ }^{41}$ I Ghozali, Model Persamaan Struktural Konsep Dan Aplikasi Dengan Program Amos 21 (Semarang: Abadi Progress, 2013).

42 Ibid.

43 Ibid.

${ }^{44}$ Nucci, L., Narvaes., Krettenauer, Handbook of Moral and Character Education. 
geng, kehamilan remaja, dan kinerja akademik yang lebih rendah. Yang terbaik, pendidikan karakter mengintegrasikan nilai-nilai tertentu ke dalam setiap aspek hari sekolah. ${ }^{45}$

Klasifikasi kemerosotan moral yang terjadi di sekolah Advent dibagi dua yaitu perilaku, dan tindakan. Mengucapkan kata-kata kotor, tidak peduli terhadap penderitaan dan masalah orang lain, anti-sosial adalah perilaku-perilaku negatif. Menggunakan pakaian tidak sopan, mencuri, menonton pornografi, mengonsumsi minuman keras dan obat-obatan adalah tindakan negatif. Agama adalah sistem kepercayaan yang akan memperkuat moralitas manusia. Peribadatan/kebaktian yang dilakukan setiap pagi dikelas masing-masing dapat mencegah orang melakukan tindakan tidak bermoral dan mempererat hubungan pribadi manusia dengan Tuhan. Solusi terbaik yang dapat dilakukan oleh pihak-pihak berkepentingan adalah dengan melakukan peningkatan kualitas karakter melalui pendidikan agama.

Kohlberg memberikan tahapan seseorang untuk pembentukan moral. Tahap pertama adalah tahap seorang anak percaya bahwa tindakan yang paling tepat adalah bekerja sama dengan otoritas untuk mencegah hukuman. ${ }^{46}$ Tahap kedua; seorang anak sudah mengerti dirinya dan percaya bahwa dia dan orang lain harus mendapat manfaat dari interaksi sosial apa pun. Tahap ketiga; Seorang anak mengambil perspektif kelompok dan percaya bahwa itu adalah pilihan terbaik untuk dapat menyesuaikan diri dengan norma yang berlaku. Tahap keempat; Remaja mengambil sistem atau perspektif masyarakat dan percaya bahwa ia harus mengikuti hukum demi kepentingannya sendiri untuk mempertahankan masyarakat yang beradab. Tahap kelima; Orang dewasa merumuskan prinsip moralnya, atau aturan abstrak yang mengarahkan perilaku moral.

Model pembangunan karakter untuk siswa sekolah Advent didasarkan pada teori moral Kohlberg. Pada tahap awal, kepercayaan diri dibangun melalui otoritas guru dengan konteks penurutan karena takut di hukum. Tahapan kedua, siswa mulai mengerti dirinya, dan mulai terbiasa melakukan interaksi dengan guru dan temannya. Di tahap inilah kepercayaan dirinya terbentuk. Ketika rasa percaya dirinya sudah terbentuk, guru akan lebih mudah membimbing kerohanian dan moralitasnya. Kegiatan ekstrakurikuler adalah salah satu cara untuk ikatan antara guru dan siswa. Siswa yang aktif dalam kegiatan ekstrakurikuler menjadi dekat dengan guru mereka dan menghindari pertemanan yang buruk. Tahap ketiga, siswa mulai memercayai kelompoknya. Disinilah tahap pembentukan kemandirian, tanggung jawab, dan aktif dalam interaksi sosial peer-group dibentuk. Optimalisasi peer-group harus dioptimalkan melalui proyek kolaborasi seperti melakukan penelitian, keterampilan pemecahan masalah, desain komputer, desain grafis, fotografi, penulisan puisi, penulisan lagu, dan menciptakan produk sederhana. Semua kegiatan ini harus di bawah pengawasan ketat dari guru yang ditugaskan.

Tahap keempat adalah perspektif kelompok. Siswa percaya bimbingan dari kelompok akan memberikan dukungan moral terhadap kekuatan karakter. Dukungan kelompok diperlukan untuk membentuk karakter siswa. Kelompok ini terdiri dari orang tua, komunitas gereja, dan kaum muda. Pembentukan kelompok bimbingan dimulai dengan memberikan su-

${ }^{45}$ C. Abourjilie, "Character Citizenship Service," Education (2006).

${ }^{46}$ L. Kohlberg, Morals Stages, And Moralization: The Cognitive-Developmental Approach. Moral Development And Behavior (New York: Holt, Rinehart, and Winston, 1976). 
rat undangan kepada orang-orang tertentu menanyakan kesediaan mereka untuk menjadi bagian dari kelompok mentoring. Bagi mereka yang bersedia mengikuti program ini maka akan diadakan pelatihan teknik pendampingan selama beberapa bulan dengan materi-materi ajar yang telah ditentukan. Ketika kelompok itu sudah siap menjadi pembimbing, masingmasing mereka akan membentuk kelompok yang terdiri dari 10-15 siswa. Proses pendampingan diadakan setiap hari Minggu dan Senin. Hari minggu fokus kepada pembangunan karakter dalam kelompok, dan hari Senin pembangunan karakter secara individu. Programnya dalam bentuk permainan, bercerita, proyek, kesaksian, khotbah, dan puji-pujian. Tahap kelima setiap anak diharapkan memiliki karakter yang baik.

\section{Pengaruh Pendidikan Karakter terhadap Bimbingan Konseling}

Koefisien variabel laten eksogen dari pendidikan karakter terhadap bimbingan konseling variabel laten endogen adalah -9.365 ini menunjukkan hubungan negatif, yang berarti jika pendidikan karakter tinggi, bimbingan dan konseling tidak diperlukan. Nilai t-hitung adalah 9,365 lebih besar dari batas kritis yang ditentukan 1,96, sehingga $\mathrm{H}_{2}=$ ditolak dan $\mathrm{Ha}_{2}$ diterima yang berarti ada pengaruh pendidikan karakter pada bimbingan dan konseling. Pengaruh pendidikan karakter pada bimbingan dan konseling adalah $77,8 \%$ sedangkan $22,2 \%$ dipengaruhi oleh variabel lain yang tidak diteliti.

Konsep bimbingan konseling yang terjadi selama ini adalah untuk menyelesaikan masalah siswa. Misalnya, seorang anak dipanggil oleh pembmbing konseling karena mencuri atau karena berkelahi. Bukan untuk pembimbingan prestasi pelajaran atau karir siswa. Di situlah kesenjangannya, sehingga proses bimbingan menjadi tidak efektif. Pola pikir siswa telah terbentuk bahwa hanya siswa yang sedang bermasalah saja yang perlu dibimbing.

Ada beberapa solusi yang dapat diberikan sehubungan dengan adalah agar proses pembimbingan dapat optimal. Pertama, agar membagi proses bimbingan menjadi tiga bagian yaitu bimbingan prestasi, yaitu tentang bagaimana siswa mencapai prestasi terbaiknya dan mengembangkan talentanya. Bimbingan karir; yaitu mengarahkan siswa untuk mencapai citacitanya kelak. Bimbingan masalah; yaitu mengarahkan siswa yang memiliki masalah dan memberikan jalan keluar. Kedua, agar pendidikan karakter diimplementasikan di setiap mata pelajaran oleh setiap guru. Misalnya guru matematika, saat menjelaskan materinya, agar dia menghubungkannya dengan pendidikan karakter. Ketiga, agar pendidikan karakter dikonseptualisasikan dan diintegrasikan ke dalam kurikulum yang diturunkan dalam setiap mata pelajaran sebagai bagian dari proses pembelajaran. Materi pembelajaran yang berkaitan dengan norma atau nilai-nilai untuk setiap mata pelajaran perlu dikembangkan, dieksplorasi, dan dihubungkan dengan konteks kehidupan rutin.

\section{Pengaruh Dekadensi Moral terhadap Bimbingan Konseling}

Koefisien variabel laten eksogen dekadensi moral terhadap variable bimbingan dan konseling laten endogen adalah 3,679 ini menunjukkan hubungan positif, yang berarti jika dekadensi moral tinggi, maka bimbingan dan konseling diperlukan. Nilai-t 3,679 lebih besar dari yang ditentukan batas kritis 1,96 , sehingga $\mathrm{HO}_{3}=$ ditolak dan $\mathrm{Ha}_{3}$ diterima yang berarti ada pengaruh dekadensi moral terhadap bimbingan dan konseling. Pengaruh moral dekadensi pada bimbingan dan konseling adalah 0,7\%, sedangkan 99,3\% dipengaruhi oleh variabel lain yang tidak diteliti. 
Bimbingan konseling biasanya berbicara tentang aspek psikologis; fungsi bimbingan akan sangat penting bagi siswa yang menderita gangguan psikologis, mengalami banyak masalah, dan yang tidak dapat mengikuti pelajaran dengan baik. Bimbingan konseling juga mutlak diperlukan untuk membangkitkan antusiasme untuk belajar dan memberikan pola pikir bahwa mereka adalah individu yang cerdas yang dapat bersaing dengan moral yang sehat dan tidak dapat dipengaruhi oleh tren penurunan moral saat ini. Moral sangat penting untuk dibentuk sejak usia dini sehingga anak-anak di masa depan memiliki sikap dan perilaku yang baik dan tidak menyimpang dari norma-norma yang berlaku di masyarakat. Moral anak dapat dibentuk melalui harga diri anak. Namun, habituasi juga dipengaruhi oleh lingkungan sosial anak. Situasi lingkungan merupakan salah satu faktor terpenting dalam membangun atau mengubah karakter. ${ }^{47}$ Membangun nilai-nilai moral yang baik dilingkungan sekolah adalah tugas bimbingan konseling dan guru. Mereka harus melakukan bimbingan konseling agar terwujud sebagai moralitas siswa yang baik. Itulah sebabnya pembimbing konseling sering dijuluki sebagai bengkel moral.

\section{Kesimpulan}

Melihat hubungan antar variabel maka dekadensi moral menunjukkan adanya pengaruh dan hubungan yang positif terhadap pendidikan karakter. Artinya, jika dekadensi moral tinggi maka pendidikan karakter diperlukan. Pendidikan karakter menunjukkan adanya pengaruh dan hubungan yang negatif terhadap bimbingan konseling. Artinya, jika pendidikan karakter dijalankan dengan optimal maka bimbingan konseling yang berhubungan dengan pembentukan karakter tidak diperlukan. Dekadensi moral menunjukkan pengaruh dan hubungan yang positif terhadap bimbingan konseling. Artinya, jika dekadensi moral tinggi, maka bimbingan konseling diperlukan.

Ketika ada inkonsistensi dalam mendidik anak dalam keluarga, maka terjadi dekadensi moral pada siswa didik. Salah satu cara untuk mencegah dekadensi moral yang telah terjadi di SMA Advent Jakarta adalah dengan pembentukan tabiat melalui kebaktian dan menggunakan model kerjasama segitiga sama sisi yaitu kerja sama antara pihak sekolah, orang tua dan anak. Konsepnya mirip dengan konsep diskusi kelompok. Orang tua menjadi pembimbing, dan siswa menjadi orang yang dibimbing. Kelompok ini terdiri dari dua orang tua dan beberapa anak (yang bukan anak kandung dari pembimbing) yang menjalin hubungan, kepercayaan dan dan mencapai ekspektasi yang telah mereka tentukan bersama. Implementasi pendidikan karakter yang dapat dilakukan adalah agar setiap guru mengintegrasikan setiap pelajaran yang diajarkan kepada iman dan kerohanian (integrated faith and learning). Di saat yang sama peran guru bimbingan dan konseling harus didaya-gunakan dengan memberikan pelajaran pendidikan karakter selama satu jam setiap minggu disetiap kelas. Diharapkan agar pihak Sekolah dapat mengembangkan kurikulum yang mencakup kepribadian, sikap, dan perilaku. Penerapan bimbingan konseling masih belum dimaksimalkan karena masih ada rangkap jabatan. Hanya satu sekolah yang telah memiliki guru bimbingan konseling yang tamat sarjana psikologi.

\footnotetext{
${ }^{47}$ Jeremy Jeremy and Stimson Hutagalung, "The Role of Christian Counseling Towards Character Building of High School Students in Salemba Adventist School, Jakarta Based on the Theology of Titus 2:6-7a," Abstract Proceedings International Scholars Conference 7, no. 1 (2019): 2102-2112.
} 


\section{Referensi}

Abdi, A.P. "KPAI: 24 Kasus Anak Di Sekolah Pada Awal 2019 Didominasi Kekerasan." Tirto.ID. Last modified 2019. Accessed March 25, 2020. https://tirto.id/kpai-24-kasusanak-di-sekolah-pada-awal-2019-didominasi-kekerasan-dg8o.

Abourjilie, C. "Character Citizenship Service." Education (2006).

Adaja, Tokunbo A., and Felix A. Ayodele. "Nigerian Youths and Social Media : Harnessing the Potentials for Academic Excellence.” Singaporean Journal of Business , Economics and Management Studies 1, no. 6 (2013): 56-66.

Adams, Abigail. "The Need for Character Education." International Journal of Social Sciences and Humanity Studies 3, no. 2 (2011): 23-32.

Aisyah, Aisyah. "Effect of Counseling Approach and Learning Achievement to Moral Intelligence." JETL (Journal Of Education, Teaching and Learning) 3, no. 1 (2018): 87.

Atieka, Nurul. "Character Building of Students With Counseling Services Approach." GUIDENA: Jurnal Ilmu Pendidikan, Psikologi, Bimbingan dan Konseling 4, no. 1 (2014): 12.

Bandura, A, C Barbaranelli, G. V Caprara, and C. Pastorelli. "Mechanisms of Moral Disengagement in the Exercise of Moral Agency." Journal of Personality and Social Psychology 71, no. 364-374 (1996).

Boitt, Monicah Lydia. J. "Evaluation of the Challenges in the Implementation of the Guidance and Counselling Programme in Baringo County Secondary Schools, Kenya." Journal of Education and Practice 7, no. 30 (2016): 27-34.

http://search.ebscohost.com/login.aspx?direct=true \&db=eric\&AN=EJ1118929\&site=eh ost-live.

Britwum, Francis, Edwin Adjei, Francis Nyamekye, and Bright Asante Britwum. "Perceived Causes and Effects of Moral Decadence among Some Selected Senior High Schools in the Kumasi Metropolis, Ghana." The International Journal of Humanities \& Social Studies 8, no. 5 (2020).

Chilima, Saulos Klaus. "Addressing Moral Decadence: Towards an Effective Compliance and Ethics Program †.” Africa Journal of Management 5, no. 1 (2019): 98-111.

Ekpang, P.U. "Counselling Practices As a Bench-Mark for Behaviour ModificationImplication for Youth Development." International Journal of Education and Researce 4, no. 5 (2016): 25-36.

Frye, Mike. Character Education: Informational Handbook and Guide for Support and Implementation of the Sutdent Citizen Act. 2001. orth Carolina: Department of Public Institution Division of Instructional Services, 2001.

Gao, Desheng, and Di Wang. "Rethinking 'Basic Issues' in Moral Education." ECNU Review of Education (2020): 209653112095032.

Ghozali, I. Model Persamaan Struktural Konsep Dan Aplikasi Dengan Program Amos 21. Semarang: Abadi Progress, 2013.

Giyono. Bimbingan Konseling. Yogyakarta: Media Akademi, 2015.

Hartono. "Implementasi Pendidikan Karakter Pada Layanan Bimbingan Dan Konseling." Wahana, 2011.

Hasugian, Johanes Waldes. "Kurikulum Dan Pembelajaran Warga Jemaat Dewasa Di Gereja.” KURIOS (Jurnal Teologi dan Pendidikan Agama Kristen) 5, no. 1 (2019): 3653.

Hum, Muhammad Yaumi. Pendidikan Karakater. Jakarta: Prenadamedia Group, 2014. Hutagalung, Stimson. Pendampingan Pastoral. Medan:Yayasan Kita Menulis, 2021. Hutagalung, Stimson, Bartholomeus D Nainggolan, Alvyn Cesarianto Hendriks, Yane Restuwati Walukouw, Reymand Hutabarat, Ester Karosekali, Freddy Manurung, et al. Konseling Pastoral. Medan:Yayasan Kita Menulis, 2021. 
Jeremy, Jeremy, and Stimson Hutagalung. "The Role of Christian Counseling Towards Character Building of High School Students in Salemba Adventist School, Jakarta Based on the Theology of Titus 2:6-7a." Abstract Proceedings International Scholars Conference 7, no. 1 (2019): 2102-2112.

Kiriakidis, S. P. "Moral Disengagement: Relation to Delinquency and Independence From Indices of Social Dysfunction." International Journal of Offender Therapy and Comparative Criminology 52 (2008): 583.

Kohlberg, L. Morals Stages, And Moralization: The Cognitive-Developmental Approach. Moral Development And Behavior. New York: Holt, Rinehart, and Winston, 1976.

Lickona, Thomas. Pendidikan Karakter. BandungL Nusa Media, 2008.

Lumamuly, Pitersina Christina. "The Role of Christian Religious Education Teacher in Preventing and Resolving Student Conflicts." KURIOS (Jurnal Teologi dan Pendidikan Agama Kristen) 7, no. 1 (2021): 53-60.

Mallinckrodt, Brent. "Addressing the Decline in Counseling and Supervision Process and Outcome Research in the Journal of Counseling Psychology." The Counseling Psychologist 39, no. 5 (2011): 701-714.

Morrow, David R. Moral Reasoning. USA:Oxford University Press, n.d.

Nucci, L., Narvaes., Krettenauer, T. Handbook of Moral and Character Education. New York: Routledge, 2014.

Nurhasanah, Nurhasanah, and Qathrin Nida. "Character Building of Students By Guidance and Counseling Teachers Through Guidance and Counseling Services.” Jurnal Ilmiah Peuradeun 4, no. 1 (2016): 65.

Samani, and Hariyanto. Pendidikan Karakter. Bandung: Remaja Rosdakarya Offset, 2016.

Saragih, Hisarma, Stimson Hutagalung, Arin Tentrem Mawati, Dina Chamidah, Muh. Fihris Khalik, Sahri, Paulina Wula, Bonaraja Purba, Sri Rezeki Fransiska Purba, and Iskandar Kato. Filsafat Pendidikan. Medan:Yayasan Kita Menulis, 2021.

Sevinc, Kenan, Sibel Tasci, and Elif Demir. "Some Problems of Psychological Counseling and Guidance System in Turkey." Procedia - Social and Behavioral Sciences 46 (2012): 1056-1063. http://dx.doi.org/10.1016/j.sbspro.2012.05.248.

Snyder, Mitchael. "There Are 1.4 Million Gang Members In The United States And More Pour Into The Country Every Single Day, Mould,." Mould (2020).

www.mouood.com/articles/occidentology/448-there-are-1-4-million-gang-members-inthe-united-states-and-more-pour-into-the-country-every-single-day.html. .

Sudarmanto, Eko, Ardhariksa Zukhruf Kurniullah, Erika Revida, Rolyana Ferinia, Marisi Butarbutar, Leon A Abdilah, Andriasan Sudarso, et al. Desain Penelitian Bisnis: Pendekatan Kuantitatif. Medan:Yayasan Kita Menulis, 2021.

Tuchili, Abigail Mukuwa. "Effects of Guidance and Counselling Services on Students' Interpersonal, Study, Vocational and Problem-Solving Skills in Selected Public Universities in Zambia." International Journal of Humanities, Social Sciences and Education 3, no. 12 (2016).

Turiel, Elliot. The Culture of Morality:Social Development, Context, and Conflict. UK:Cambridge University Press, 2004.

Tuttle, Harold S. Character Education: A Literature Review. Temescal Association:2015, 2015.

"Character Education." Religious Education 26, no. 8 (1931): 631-636.

Winton, Sue. "Character Education: Implications for Critical Democracy" 1, no. 1 (2012). 